\title{
Fluid induced formation of garnet coronas around scapolite: A petrological, geochemical and mass- balance approach
}

\author{
H. SOMMER1, D. JACOB2, A. KRÖNER3 \\ ${ }^{1}$ Department of Geology, The University of Namibia, \\ Southern Campus, Windhoek, Namibia, e-mail: \\ info@holgersommer.de \\ ${ }^{2}$ Australian Research Council Centre of Excellence for Core \\ to Crust Fluid Systems and Department of Earth and \\ Environmental Sciences, Macquarie University, North \\ Ryde, NSW 2109, Sydney, Australia \\ ${ }^{3}$ Beijing SHRIMP Centre, Chinese Academy of Geological \\ Sciences, 26 Baiwanzhuang Road, 100037, China
}

This study investigates garnet corona textures in highgrade granulite facies meta-anorthosites from south central Tanzania. Garnet coronas form due to drastic changes in P-T conditions leading to instability of certain minerals and, consequently, to a change in the mineral paragenesis for a given bulk rock chemical composition. The garnet corona textures from this study, separate an metastable magmatic core inside the corona from the surrounding matrix minerals. In contrast to previous investigations, the garnet in the matrix are formed prograde by isobaric heating, followed by isothermal compression and finally in a second stage garnet coronas are formed by isobaric cooling. The garnet corona forming reaction was triggered by an internal fluid flux released by the breakdown of scapolite during prograde metamorphism. Three types of garnet coronas could be identified; (i) garnet corona around metastable magmatic ilmenite rimmed by titanite, plagioclase and clinopyroxene, which is a product of the breakdown reaction of scapolite. (ii) garnet corona around original plagioclase and clinopyroxene, and (iii) garnet corona around metastable magmatic chalcopyrite, hematite and pyrite surrounded by retrograde formed scapolithe. Peak metamorphic conditions at $\sim 780^{\circ} \mathrm{C}$ and $\sim 12.4 \mathrm{kbar}$ have been identified for the suggested anticlockwise P-T path. To get evidence of the main rock forming mineral reactions during high grade metamorphism, Laser ICPMS analyes have been carried out on all rock forming minerals (LREE, HFSE and HREE), which confirms the existence of the suggested mineral reactions. A mass balance approach shows that the garnet coronas are formed to $\sim 90 \%$ by the consumption of minerals inside the garnet corona. 